\title{
Predicting and Downscaling ENSO Impacts on Intraseasonal Precipitation Statistics in California: The 1997/98 Event
}

\author{
Alexander Gershunov And Tim P. Barnett \\ Climate Research Division, Scripps Institution of Oceanography, University of California, San Diego, \\ La Jolla, California \\ DANIEL R. CAYAN \\ Climate Research Division, Scripps Institution of Oceanography, University of California, San Diego, and \\ Water Resources Division, U.S. Geological Survey, La Jolla, California \\ TONY TUBBS \\ Climate Research Division, Scripps Institution of Oceanography, University of California, San Diego, \\ Water Resources Division, U.S. Geological Survey, La Jolla, California \\ LISA GODDARD* \\ International Research Institute for Climate Prediction, Scripps Institution of Oceanography, \\ University of California, San Diego, La Jolla, California
}

(Manuscript received 10 June 1999, in final form 1 March 2000)

ABSTRACT

\begin{abstract}
Three long-range forecasting methods have been evaluated for prediction and downscaling of seasonal and intraseasonal precipitation statistics in California. Full-statistical, hybrid-dynamical-statistical and full-dynamical approaches have been used to forecast El Niño-Southern Oscillation (ENSO)-related total precipitation, daily precipitation frequency, and average intensity anomalies during the January-March season. For El Niño winters, the hybrid approach emerges as the best performer, while La Niña forecasting skill is poor. The full-statistical forecasting method features reasonable forecasting skill for both La Niña and El Niño winters. The performance of the full-dynamical approach could not be evaluated as rigorously as that of the other two forecasting schemes. Although the full-dynamical forecasting approach is expected to outperform simpler forecasting schemes in the long run, evidence is presented to conclude that, at present, the full-dynamical forecasting approach is the least viable of the three, at least in California. The authors suggest that operational forecasting of any intraseasonal temperature, precipitation, or streamflow statistic derivable from the available records is possible now for ENSOextreme years.
\end{abstract}

\section{Introduction}

It is well known that the El Niño-Southern Oscillation (ENSO) has a significant effect on California precipitation. ENSO forcing of the seasonal total rainfall is accomplished through the modulation of high-fre-

\footnotetext{
* Current affiliation: International Research Institute for Climate Prediction, Lamont-Doherty Earth Observatory of Columbia University, Palisades, New York.

Corresponding author address: Dr. Alexander Gershunov, Climate Research Division, Scripps Institution of Oceanography, University of California, San Diego, 9500 Gilman Drive, La Jolla, CA 92093 0224.

E-mail: sasha@ucsd.edu
}

quency precipitation statistics. For instance, Cayan et al. (1999) show that the sensitivity of precipitation frequency to ENSO increases with precipitation intensity over the western United States. Given a long-lead forecast of an ENSO extreme, simple statistical models can do a reasonable job of predicting high-frequency precipitation and temperature statistics in parts of the United States (Gershunov 1998), but an atmospheric general circulation model (AGCM) misses important aspects of the ENSO signal in seasonal statistics of daily precipitation and temperature (Gershunov and Barnett 1998a). AGCM-nested regional dynamical models (RDMs), however, appear to be capable of sharpening (improving) the statistics of high-frequency rainfall toward more realism on finer space scales and timescales (Chen et al. 1999; Hong and Leetmaa 1999; Mo et al. 2000). 
Long-range forecasting with RDMs unfortunately is computationally very expensive and, because of the lack of an RDM "climatology," there is no possibility at present to rigorously assess the skill of such forecasts.

Given that AGCMs are capable of capturing the ENSO signal in seasonally averaged quantities of such well-behaved variables as geopotential heights (e.g., Graham and Barnett 1995), a hybrid dynamical-statistical long-range forecasting approach is considered. This approach uses seasonal 700-hPa heights from an AGCM forced with a long-lead forecast of tropical Pacific sea surface temperature (SST) and a statistical relationship to downscale this seasonal circulation pattern to daily precipitation statistics over California. Skill is assessed rigorously via cross validation, and the performance of this hybrid model is compared with that of the purely statistical approach. The accuracies of long-lead forecasts for January-March (JFM) 1998 made by the statistical, hybrid, and fully dynamical (e.g., RDM) methods are intercompared.

\section{Data and methods}

All three forecasting approaches are based on the same premise, that ENSO extremes are predictable; therefore, each begins with a long-lead forecast of tropical Pacific SST. This first, shared step represents the first tier in a multitiered forecasting scheme. The twotiered scheme is introduced by Bengtsson et al. (1993) and Barnett et al. (1994). The three approaches differ in what comes next. The full-dynamical and hybrid approaches are essentially three-tiered schemes. The second tier is accomplished with an AGCM forced by forecast SST from the first tier. A downscaling of the AGCM result is the third tier of the forecast. In the full-dynamical approach, this downscaling is accomplished by nested RDMs, and, in the hybrid approach, the downscaling is performed using a statistical relationship. The purely statistical approach is the second tier in a two-tiered scheme. Here, the downscaling is implicit in the spatial resolution of the data used.

\section{a. Data}

A dense network of quality stations in California has been compiled from two National Climatic Data Center datasets (USA187 and First-Order Summary of the Day) and one Western Regional Climate Center dataset (WEST11). These 124 stations (dots in Figs. 2-4) have recorded daily data more or less continuously since 1950. Out of the daily data, we have constructed three variables for the JFM season: seasonal total precipitation, precipitation frequency defined as the number of days with measurable rainfall, and daily average intensity defined as the average precipitation amount per rainy day (total/frequency). We focus on these three variables to evaluate the three forecasting schemes. The statistical model and the downscaling component of the hybrid model were trained on the 46-yr period of 195095. ENSO-active winters are defined to occur when December-February Niño-3.4 detrended SST exceeds its one-standard-deviation $(1 \sigma)$ threshold. El Niño years are defined to be 1958, 1966, 1969, 1973, 1983, 1987, and 1992, and La Niña years are 1950, 1956, 1971, 1974, 1976, 1985, and 1989. Practical reasons for this definition are discussed by Gershunov (1998).

\section{b. Forecasting methods}

\section{1) Statistical scheme}

The statistical forecasting approach is the ENSOphase model described in detail by Gershunov (1998). This type of forecast essentially consists of appropriately defined and adjusted canonical El Niño (or La Niña) signals derived from the observational record. It operates on empirical quantile-transformed data to minimize bias from large outliers (see Gershunov 1998). This model uses no intensity information beyond the $\pm 1 \sigma$ Niño-3.4 SST threshold used here to define ENSO phase. Clearly, for the sole purpose of predicting climate anomalies associated with the extraordinarily intense 1997-98 event, a higher threshold choice would have been justified. Nevertheless, we chose a conservative threshold to provide enough observed cases for meaningful skill estimation. This choice undoubtedly degraded the accuracy of the JFM 1998 statistical forecast (see below).

Skill is estimated via cross validation as follows. For each El Niño winter, the squared deviations from the mean of the remaining El Niño winters are computed at each station for each precipitation variable defined above. Summation of this quantity over all El Niño events gives the warm ENSO error sum of squares,

$$
\mathrm{ESS}_{w}=\sum_{k=1}^{N_{w}}\left[p_{k}-p_{k}^{*}(-k)\right]^{2},
$$

from which the cross-validated proportion of variance explained $\left(R_{\mathrm{cv}}^{2}\right)$ by the statistical model is calculated for all El Niño winters on record:

$$
R_{\mathrm{cv}}^{2}(w)=1-\frac{\mathrm{ESS}_{w}}{\mathrm{TSS}_{w}},
$$

where

$$
\mathrm{TSS}_{w}=\sum_{k=1}^{N_{w}}\left(p_{k}-\bar{p}\right)^{2} .
$$

Here, $p$ is precipitation total, frequency, or intensity; $k$ indexes warm-ENSO-episode winters; $N_{w}$ is the total number of warm-ENSO-episode winters; and $p_{k}^{*}(-k)$ is the forecast for winter $k$ made with the model constructed without winter $k$ (this is the cross validation). For the ENSO phase model, $p_{k}^{*}(-k)$ is the mean of $p$ for all El Niño winters excluding winter $k$. Here $\mathrm{TSS}_{w}$ is the total sum of squares for El Niño winters, where 
$\bar{p}$ is the climatological mean of $p$ computed from all winters in the 46-winter climatology. The El Niño $R_{\mathrm{cv}}^{2}$, $R_{\mathrm{cv}}^{2}(w)$, for the statistical scheme is displayed in Fig. 2 (top panels). The La Niña $R_{\mathrm{cv}}^{2}, R_{\mathrm{cv}}^{2}(c)$, is similarly computed from cold-ENSO-episode data (Fig. 3, top panels).

Statistical significance testing of the $R_{\mathrm{cv}}^{2}$ measure was performed via the bootstrap (Efron 1982) by repeatedly randomly subsampling the 46-winter climatology. Seven winters (here, $N_{w}=N_{c}=7$ ) were randomly chosen and used to compute accidental $R_{\mathrm{cv}}^{2}$ as described above for ENSO-extreme years. This procedure was repeated 100 times to make up the accidental distribution of skill. Statistical significance was assessed by comparing actual El Niño and La Niña skill $\left[R_{\mathrm{cv}}^{2}(w)\right.$ and $\left.R_{\mathrm{cv}}^{2}(c)\right]$ to the 90th, 95th and 99th percentiles of the accidental skill distribution. Statistical significance at these three levels is denoted by three levels of shading on Figs. 2 and 3 (top panels for the statistical model). The rigor of the cross-validation approach to skill estimation is attested to by the fact that nearly all positive skill is statistically significant.

The statistical model does not have to be a purely ENSO-based technique; low-frequency modulation of ENSO-based predictability can and should be taken into account in the operational mode (Gershunov and Barnett 1998b; Gershunov et al. 1999). In other words, the prediction $p^{*}$ for JFM 1998 could have been constructed based on an El Niño-cold North Pacific oscillation (NPO) composite. This approach has not been taken here mainly out of fairness to the other methods whose ENSO signal modulation by NPO has not been studied. ENSO thus is the only forcing and forecasting basis for the statistical model. Of course, the extent to which details of the forcing field can be incorporated into the statistical scheme is limited severely by the available degrees of freedom. Obviously, the range of possible statistical forecasts is limited to the recorded past cases.

\section{2) HYBRID SCHEME}

The hybrid approach suffers less from this historical limitation, and details of the forecast forcing field (tropical Pacific and extratropical SST) can influence results. AGCM-specific problems having to do with the authenticity of model reality come into play, however. Nevertheless, the ECHAM-3 AGCM used here does a realistic job of simulating El Niño-related seasonal circulation anomalies. This fact is evident from comparison of Figs. 1a and 1b, which show canonical ENSO anomalies in modeled (average of 10 ensemble members) and observed $700-\mathrm{hPa}$ heights. La Niña-related $700-\mathrm{hPa}$ anomalies, however, are less realistically simulated (cf. the position of modeled and observed 700-hPa anomalies in the general area of the Aleutian Low in Figs. $1 \mathrm{c}$ and 1d). This spatial bias in the AGCM circulation response to La Niña forcing is expected to deteriorate La Niña-related forecasting skill.

The approach uses an ensemble average of 10 46-yr runs (1950-95) with ECHAM-3, developed at the Max Plank Institute of the University of Hamburg, forced with observed global SST and run at T42L19 resolution. Canonical correlation analysis (CCA; Barnett and Preisendorfer 1987) is used to develop a linear relationship between the modeled JFM 700-hPa heights over the North Pacific, American, and Atlantic region $\left(20^{\circ}-70^{\circ} \mathrm{N}\right.$, $120^{\circ} \mathrm{E}-0^{\circ}$ ) and total JFM precipitation amount, daily frequency, and intensity observed at California stations. The CCA model is built on all $46 \mathrm{yr}$ of data; stratifying the model training period by ENSO-active winters does not lead to a systematic improvement in skill. It is a compliment to the AGCM that the strength of the CCA relationship (measured by skill in ENSO-active years) generally is similar to or better than that between observed $700-\mathrm{hPa}$ heights and the same precipitation variables. The reason for this somewhat surprising result is the fact that the ENSO signal in geopotential heights is reproduced reasonably well in this model, especially for El Niño winters, and sharpened via 10-member ensemble averaging. Based on results of an eigenvalue degeneracy test, nine leading canonical correlation functions were retained in the downscaling procedure. Given a (second tier) forecast of the 700-hPa heights, the CCAderived relationship between modeled $700-\mathrm{hPa}$ heights and observed precipitation statistics then is used to obtain the forecast precipitation statistics. The ECHAM-3 prediction for JFM 1998 was forced in December 1997 with the National Centers for Environmental Prediction (NCEP) dynamical-coupled-model forecast SST in the tropical Pacific, statistically forecast SST elsewhere in the Tropics, and observed November, 1997, SST anomalies "persisted" on the 1961-90 monthly climatology of SST in the extratropics.

El Niño- and La Niña-related skill is estimated by cross validation. For each winter on record, a forecast, $p_{k}^{*}(-k)$, is constructed with the CCA model trained on the remaining 45 winters. The $R_{\mathrm{cv}}^{2}(w)$ and $R_{\mathrm{cv}}^{2}(c)$ then are computed analogously to the purely statistical model as described above and displayed in Figs. 2 and 3, respectively (bottom panels). Statistical significance is also estimated as for the purely statistical scheme by repeating the $R_{\mathrm{cv}}^{2}$ calculation for 100 random sevenmember composites (again, consistent with seven El Niño and seven La Niña events on record), creating a distribution of random CCA skill. Skill due to El Niño and La Niña forcing $\left[R_{\mathrm{cv}}^{2}(w)\right.$ and $\left.R_{\mathrm{cv}}^{2}(c)\right]$ then is compared with appropriate quantiles of this random skill distribution to assess statistical significance. As for the purely statistical model, levels of shading in Figs. 2 and 3 (bottom panels) represent the levels of hybrid-model skill significance. As with the statistical model, because of the rigor of the skill-estimation methodology, "positive" hybrid-model skill is nearly synonymous with "significant" skill.

\section{3) DyNAMICAL SCHEME}

The dynamical approach uses the Regional Spectral Model (RSM; Juang and Kanamitsu 1994; Juang et al. 
a) MODEL EI Nino Pattern (gpm)

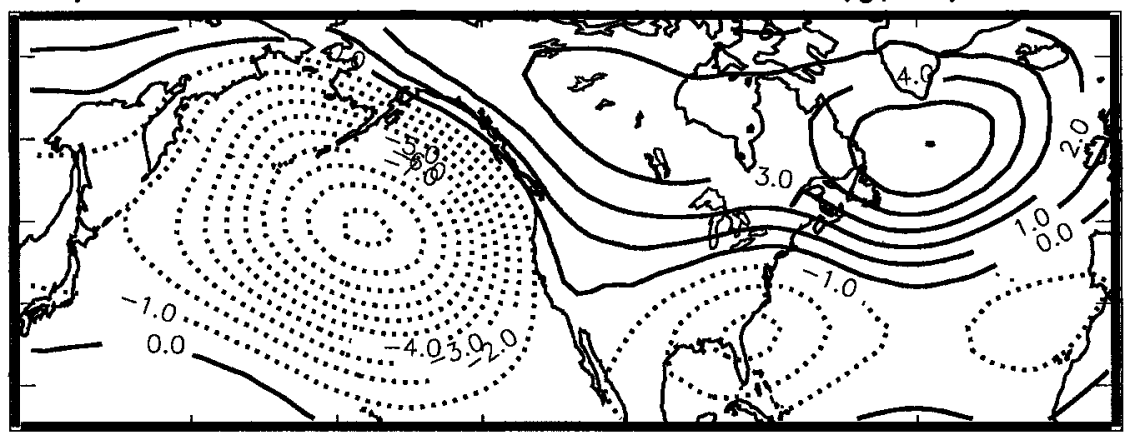

b) OBSERVED El Nino Pattern (gpm)

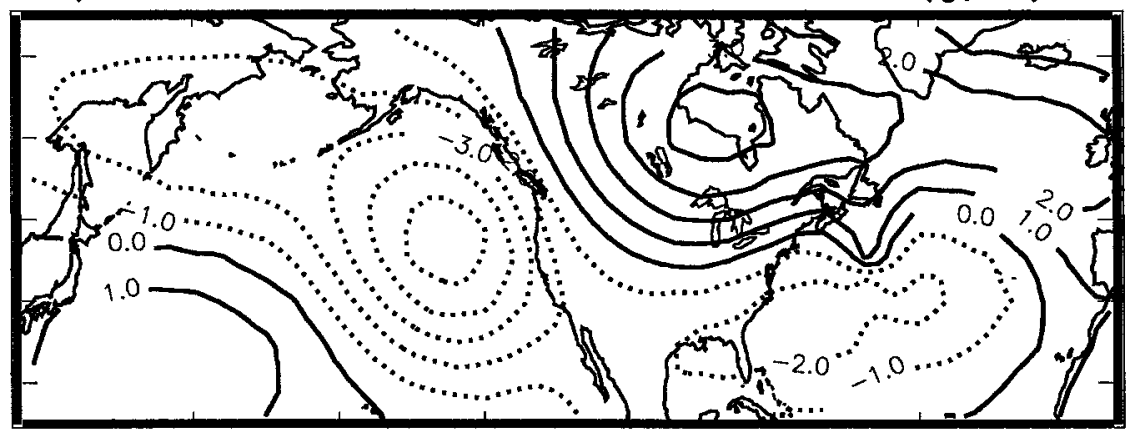

c) MODEL La Nina Pattern (gpm)

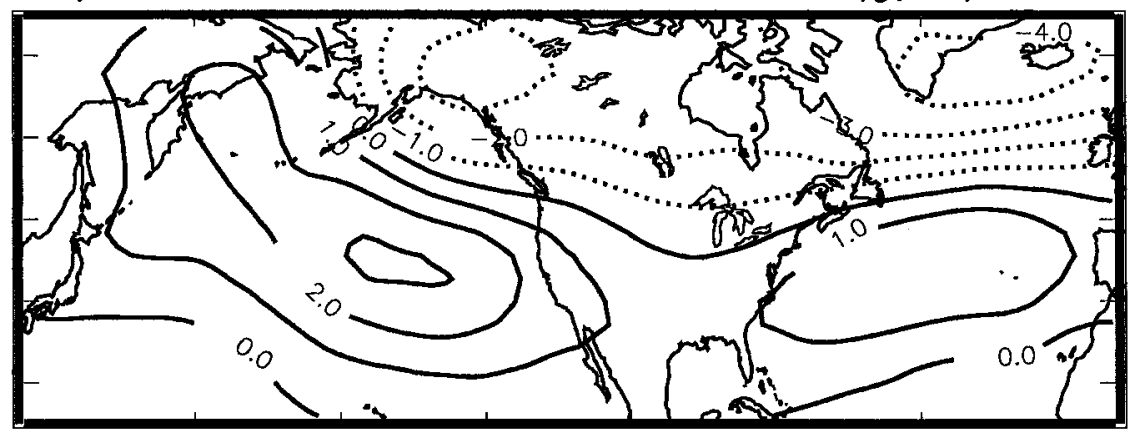

d)

OBSERVED La Nina Pattern (gpm)

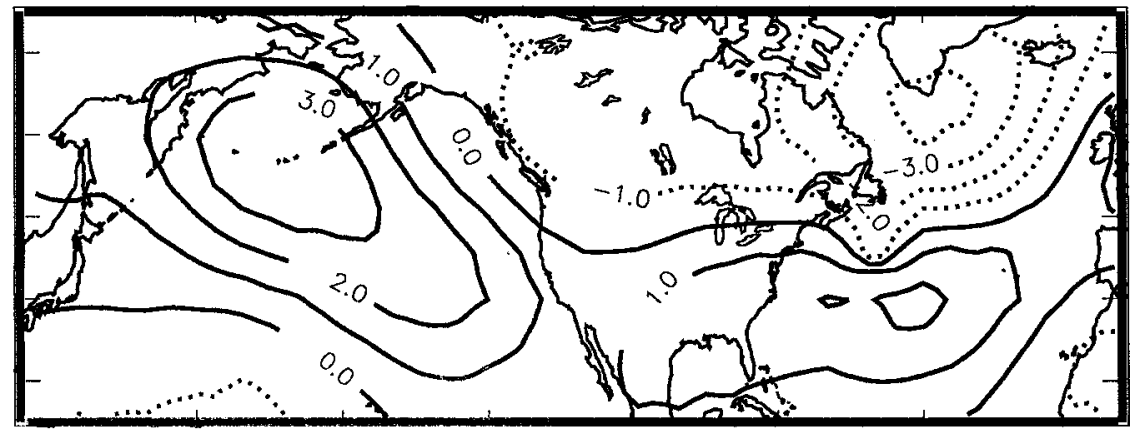

FIG. 1. Canonical 700-hPa JFM anomalies in geopotential meters. El Niño [(a) and (b)] and La Niña [(c) and (d)] anomalies from ECHAM-3 [(a) and (c)] and observations [(b) and (d)]. See text for the list of El Niño and La Niña years. Contour interval is $1 \mathrm{~m}$. Positive (negative) contours are solid (dashed). The zero contour is thickened. The relative strength of modeled to observed El Niño anomalies is related to the sharpening of the ENSO signal through ensemble averaging. A 10-member ensemble was used in this case. 


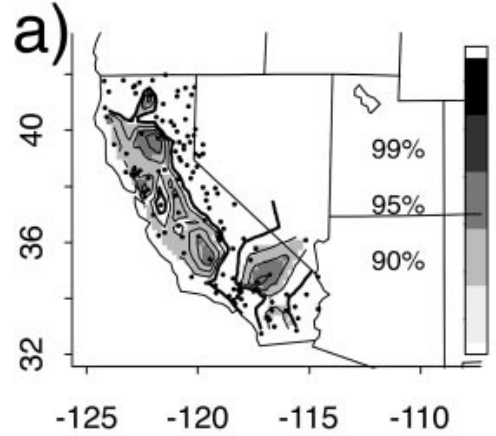

JFM Total

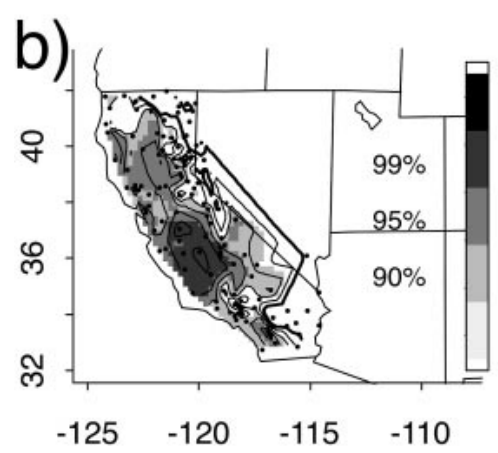

JFM Total

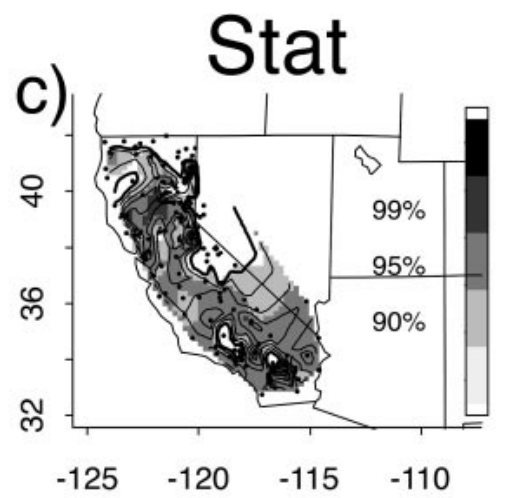

Frequency

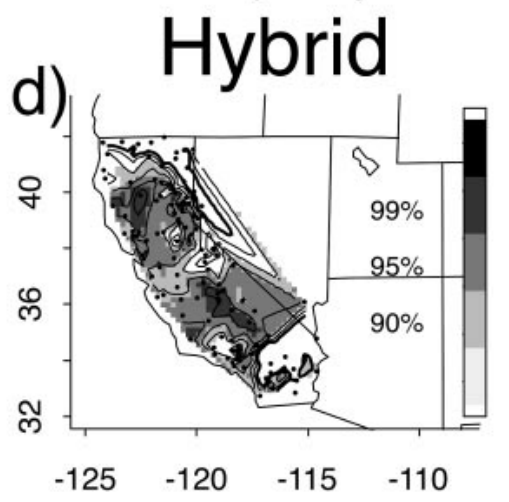

Frequency

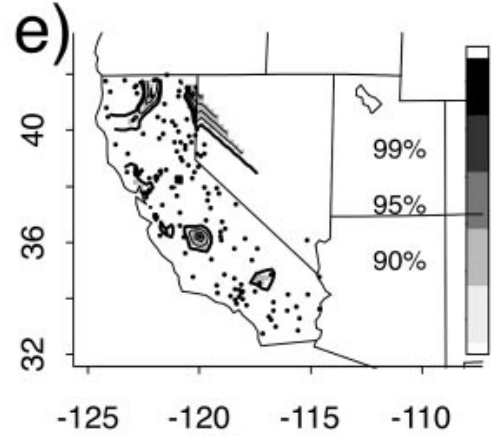

Intensity

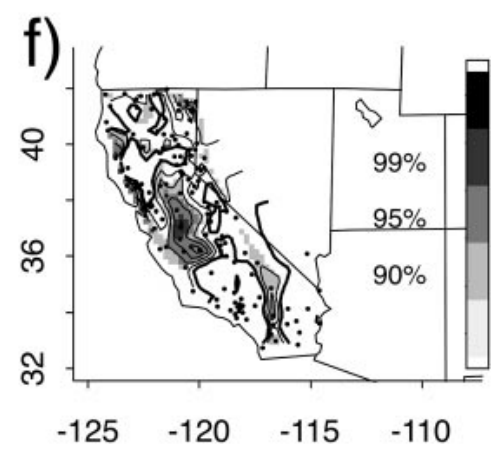

Intensity

FIG. 2. Cross-validated $R^{2}\left(R_{\mathrm{cv}}^{2}\right)$ forecast skill for El Niño winters (JFM) from the full-statistical [(a), (c), and (e)] and hybrid models [(b), (d), and (f)] for total JFM precipitation [(a) and (b)], precipitation frequency [(c) and (d)], and average daily intensity [(e) and (f)]. Units are in proportion of variance (deviation from the 46-yr mean) explained for El Niño winters on record. Contours are drawn at 0.1 intervals. The zero contour is thickened; negative values of $R_{\mathrm{cv}}^{2}$ are not displayed. Values significant at the $90 \%, 95 \%$, and $99 \%$ levels are lightly, medium, and darkly shaded, respectively. Dots denote station locations.

1997) developed at NCEP. This model has been extensively operated and evaluated in several recent investigations (Hong and Leetmaa 1999; Mo et al. 2000; Roads and Chen 1999, manuscript submitted to J. Geophys. Res.). High-resolution (25 and $10 \mathrm{~km}$ ) versions of RSM have been evaluated and used to model California and southwestern U.S. climate by Chen et al. (1999) and Anderson et al. (2000).

The model integrations used here were performed at the International Research Institute for Climate Prediction by double, one-way nesting (i.e., nesting applied twice without feedback from the small domain to the outer domain) of RSM in the ECHAM-3 AGCM, which is run at T42L19 resolution. An ECHAM-3 forecast for JFM 1998, similar to that from which the 700-hPa heights were used in the hybrid scheme, was used to drive RSM. The first nest of RSM downscales the AGCM to $80 \mathrm{~km}$ over the eastern North Pacific and most of the United States $\left(17^{\circ}-57^{\circ} \mathrm{N}, 155^{\circ}-82^{\circ} \mathrm{W}\right)$. The time step of RSM is $20 \mathrm{~min}$, and the large-scale flow input from the AGCM is updated every $6 \mathrm{~h}$. The atmospheric circulation from the $80-\mathrm{km}$ nested region then serves as input to a smaller region imbedded over California and Nevada $\left(33^{\circ}-42^{\circ} \mathrm{N}, 125^{\circ}-113^{\circ} \mathrm{W}\right)$ resolved at $20 \mathrm{~km}$. Placement of boundaries is consistent with the U.S. regional downscaling of other groups (e.g., Experimental Climate Prediction Center, Climate Prediction Center, and Center for Ocean-Land-Atmosphere Studies). According to Hong and Leetmaa (1999), the RSM results do not depend critically on boundary locations. Further work clearly needs to be done to assess the performance of this downscaling procedure. With only one season, it is impossible to judge its ability to simulate the mean climate and thus to judge its ability to improve the simulation/prediction of the AGCM.

The dynamical approach is fully (nonlinearly) sensitive to details of the SST forcing field. Because more than just the best-behaved variables from the AGCM are used as boundary conditions for the nested RSM and no explicit reality control (such as the statistical component of the hybrid method) is built into the scheme, this method is the one most prone to misbehavior arising from error growth. Potential for error growth is also enhanced because of the need to param- 


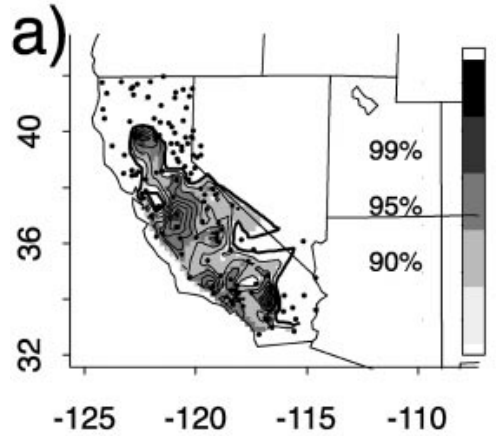

JFM Total

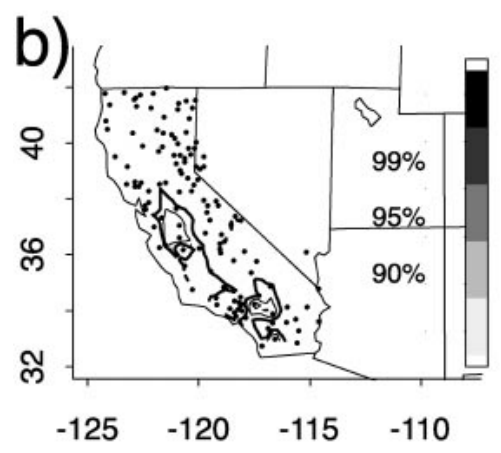

JFM Total

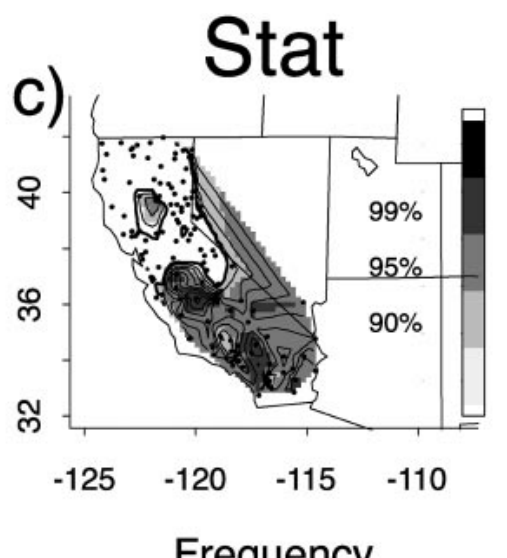

Frequency Hybrid

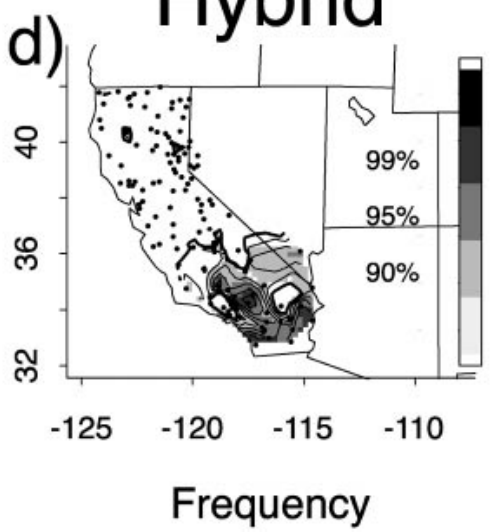

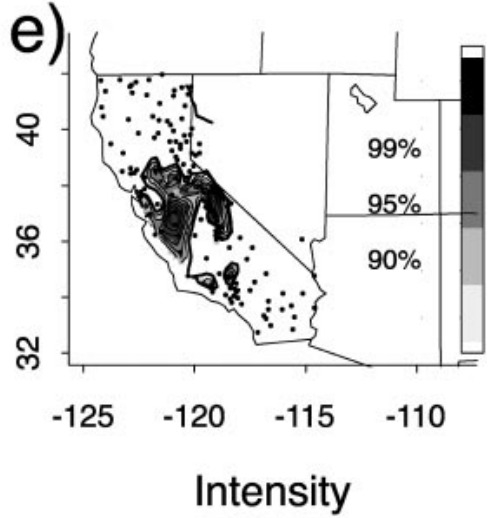

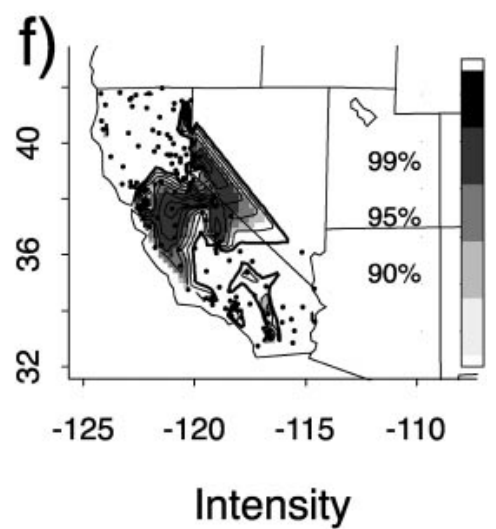

FIG. 3. Same as Fig. 2 but for La Niña winters (JFM).

eterize processes not resolved by RSM. The average of a three-member ensemble AGCM-RSM forecast is used to sharpen the signal-to-noise ratio. Because history is not a limiting factor, the full-dynamical approach is the most versatile method of the three. The computational demands of the dynamical scheme result in a current lack of an RSM climatology, which makes it impossible to assess the skill of this method in the rigorous crossvalidated fashion of the statistical and hybrid schemes. The best we can do for now is to compare the performance of the dynamical scheme with that of the two others for specific ENSO-extreme years. This approach is used below for the JFM 1998 El Niño.

\section{Results}

\section{a. Statistical and hybrid model skill}

Forecast skill is assessed for the statistical and hybrid models as the cross-validated proportion of total variance explained $\left(R_{\mathrm{cv}}^{2}\right)$ for El Niño and La Niña winters as described above. Because observed SST is used to drive the models in this calculation, this skill measure is, strictly speaking, a measure of "specification skill," representing an optimistic estimate of true forecast skill that would use forecast SST in the first tier of the forecasting scheme. It is difficult to estimate how much the use of observed SST biases the skill measure, but the skill estimate for the statistical scheme should be least affected because the full-statistical method requires a far-simpler SST forecast in the first tier. This having been said, let us now examine the estimated forecast skill for the statistical and hybrid forecasting approaches.

Figure 2 presents $R_{\mathrm{cv}}^{2}$ for El Niño winters. Figures $2 \mathrm{a}, \mathrm{b}$ show the skill of forecasting total JFM precipitation with the statistical and hybrid models, respectively. Both approaches display positive skill over most of California, but the hybrid model shows skill improvements in both spatial extent and magnitude. Generally, where the statistical model explains $20 \%-30 \%$ of total rainfall variability, the hybrid model explains 40\%-50\%. Moreover, the hybrid model covers more area of California with positive skill. Notable, although low, positive skill appears in the Sierra Nevada.

Statistical- and hybrid-model skills for precipitation frequency (Figs. 2c,d) generally are comparable to those for total precipitation. The statistical model may do somewhat better in forecasting frequency than in fore- 
casting total precipitation, especially in the vicinity of the San Francisco Bay Area and the northern Sierra Nevada. Still, the hybrid model shows incremental increases in forecasting skill in many regions, especially central California. Precipitation intensity (Figs. 2e,f) may be almost entirely unpredictable with the statistical model, whereas the hybrid model does a reasonable job in some regions, most notably in the central valley, where it accounts for over $30 \%$ of total variance explained. On the whole, for El Niño winters, average daily intensity is the most poorly predicted precipitation variable of the three variables considered. The hybrid model is consistently better than the pure statistical approach, although it has consistent problems in southeastern California.

We have compared the hybrid-model skill maps with specification skill based on observed 700-hPa heights and also with similar skill maps based on a subsample of the rainfall observing stations and a varying number of CCA modes. These results (not shown) reveal that the hybrid-model El Niño skill deficiency in the southeast does not stem from problems in the predictor field (modeled 700-hPa height anomaly), but rather from details of the downscaling scheme. Regional optimization of the CCA downscaling scheme would be a worthwhile undertaking, which is beyond the scope of this paper, but deserves to be the topic of a separate investigation.

Figure 3 shows $R_{\mathrm{cv}}^{2}$ for La Niña winters on record. Now the situation is comparatively changed and the statistical model may outperform the hybrid model in at least two out of three precipitation variables: total and frequency. The statistical model appears to perform equally well in general during El Niño and La Niña winters. Total precipitation is specified better for cold (vs warm) ENSO winters in central California and the coastal regions in the southern half of the state, while no skill is evident in far-northern California. Frequency shows similar improvements in the south with a deterioration of skill in northern California. Daily intensity is skillfully forecast in the center of the state during La Niña winters. Values of $R_{\mathrm{cv}}^{2}$ above $50 \%$ appear at several stations in central California for all three variables (Figs. $3 a, c, e)$.

The hybrid model performs notably worse during La Niña winters for all variables (Figs. 3b,d) with the possible exception of intensity (Fig. 3f). This deterioration of the hybrid-model skill for La Niña winters is evident in comparison with the statistical model's La Niña skill (Figs. 3a,c,e) and also in comparison with the hybridmodel performance during El Niño winters (Figs. $2 \mathrm{~b}, \mathrm{~d}, \mathrm{f})$. Forecasting skill for total precipitation does not rise much over $20 \%$ and that only at a few stations. There is no skill over most of California. Useful precipitation-frequency forecasting skill is confined to southernmost California, while intensity is forecast very well (skill over 50\%) but only in the central portion of the state. The hybrid model's poor La Niña performance is due to the AGCM's bias in simulating the predictor field (700-hPa geopotential level; cf. Figs. 1c and 1d). ECHAM-3's ENSO response is too linear over the northeastern Pacific, which is not the case in nature [see Hoerling et al. (1997) and Figs. 1b,d]. The model linearity, in combination with the linear nature of the downscaling scheme, effectively compels the hybridmodel La Niña forecasts to be the inverse qualitatively of the El Niño forecasts. This situation may be improved by using a different AGCM and/or by optimal selection of canonical modes to represent the El Niño and La Niña signals separately.

\section{b. All three models validated for JFM 1998}

True forecasting performance of the statistical-, hybrid-, and dynamical-forecasting approaches is summarized for the specific winter of JFM, 1998, in Fig. 4. The statistical model forecast was based on the understanding that a strong El Niño winter is imminent. This likelihood was abundantly clear by late summer of 1997 and no more-sophisticated SST forecast was required to perform the statistical forecasts. The first-tier (SST) forecasts used by the hybrid method were made in November 1997 as described in the forecasting-methods section above. The same synthesized SST forecast carried out in December 1997 formed the basis of the fully dynamical California precipitation forecast.

The statistical model underestimated total rainfall for most of California. It underestimated rainfall frequency at about half of the stations but did reasonably well at other stations, notably in areas of good forecasting skill (Fig. 2c). Daily intensity was forecast well at a large majority of the stations and underestimated at only a few scattered stations. Daily intensity was forecast the best of the three variables by the statistical model for JFM of 1998 despite that variable being associated with the poorest skill during El Niño winters in the record (Fig. 2e). This result underscores the danger of evaluating forecast models based on only one case.

The intense 1997/98 El Niño produced total JFM precipitation anomalies that were almost identical to those of JFM of 1983, the other intense El Niño in the record. A statistical forecast for JFM of 1998 based on just the three strongest El Niños on record would have been more accurate. Although skill estimation based on a sample of three cases may be called into question, such a constraint may have been justified given the unusual intensity of the 1997 El Niño. In general, though, magnitude and stability of ENSO-related U.S. temperature and precipitation anomalies are not always positively correlated with ENSO intensity (Gershunov 1998).

The hybrid model did an excellent job forecasting all three precipitation variables for JFM of 1998. Overestimation is a common problem that is constrained mainly to southern California, where hybrid-model El Niño skill tends to be poor. The AGCM was very sensitive to unusually strong tropical SST forcing (and maybe also to cold North Pacific SST anomalies), and even the 


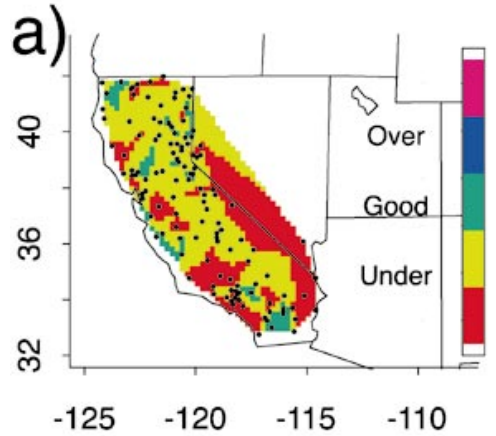

Total $(\mathrm{m})$

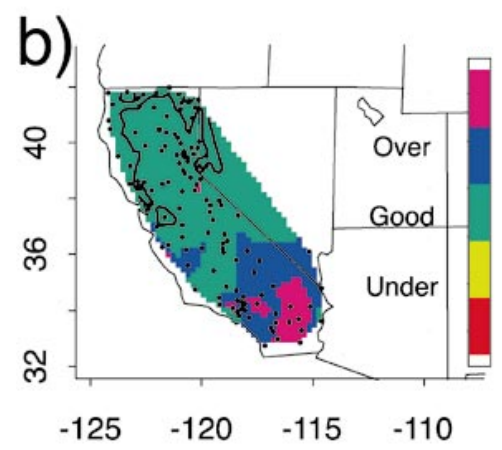

Total $(m)$

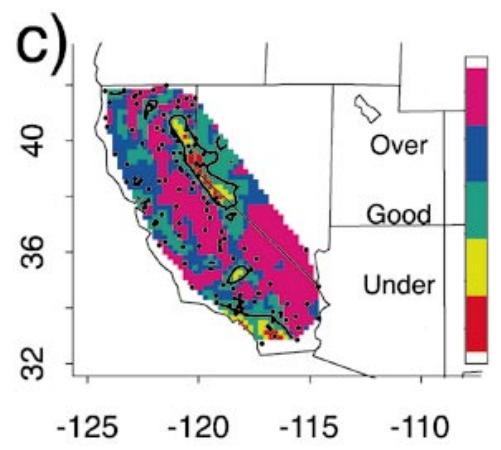

Total $(m)$

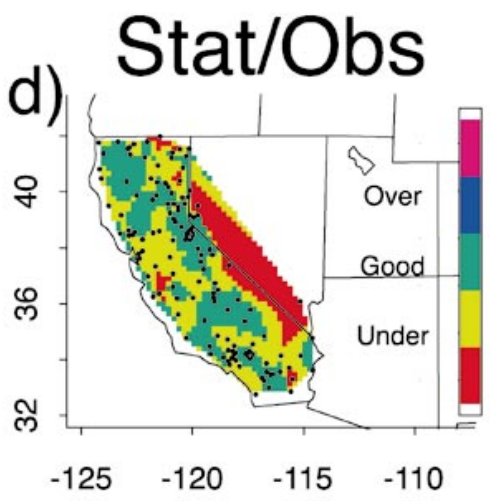

Frequency (days) Hybrid/Obs

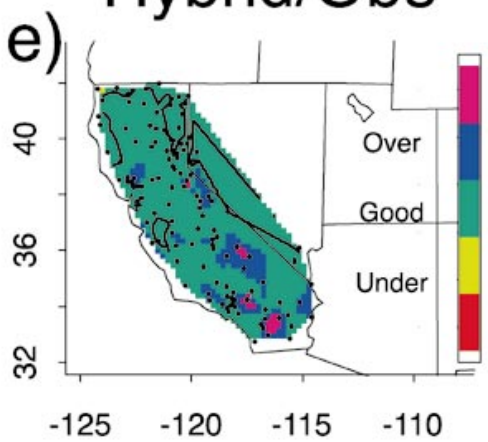

Frequency (days)

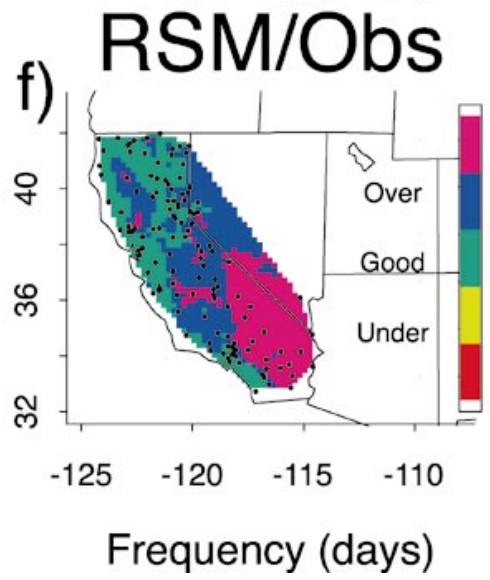

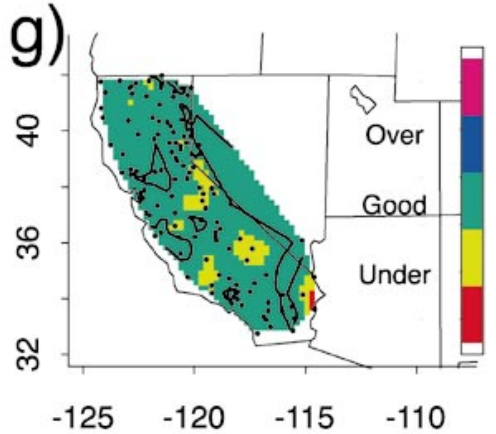

Intensity (mm)

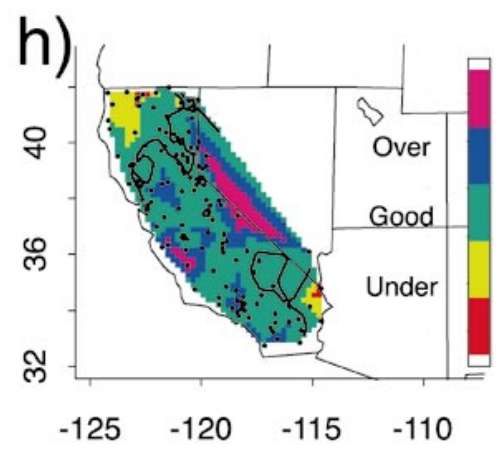

Intensity ( $\mathrm{mm})$

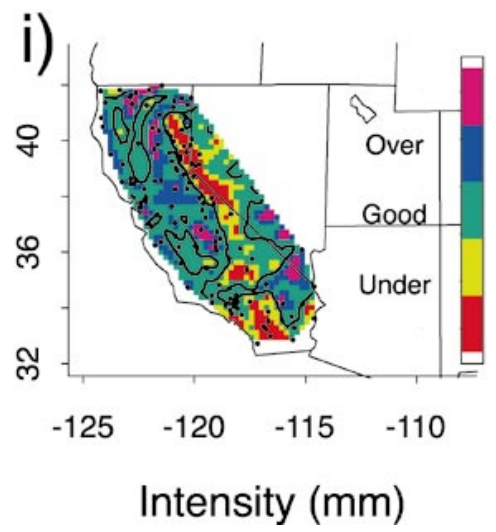

FIG. 4. JFM, 1998, forecast validation displayed as ratio of forecast to observations. A good forecast (green color) is considered to be within $50 \%$ of observations. Two categories of overestimation (blue and purple) and underestimation (yellow and red) denote forecasts that deviate from observations by $50 \%-100 \%$ and more than $100 \%$, respectively. Total JFM precipitation validations [(a), (b), (c)], precipitation frequency validations $[(\mathrm{d}),(\mathrm{e}),(\mathrm{f})]$ and average daily intensity $[(\mathrm{g}),(\mathrm{h}),(\mathrm{i})]$ are displayed for the statistical $[(\mathrm{a}),(\mathrm{d}),(\mathrm{g})]$, hybrid $[(\mathrm{b}),(\mathrm{e})$, (h)], and dynamical [(c), (f), (i)], models. Dynamical forecasts are 3-member ensemble averages. Perfect forecasts are delineated with a solid contour. Dots denote station locations. All results are displayed on the RSM grid $(20 \mathrm{~km})$.

empirical downscaling scheme did not sufficiently retard the severity of strong precipitation anomaly that was forecast for JFM of 1998. The overall performance of the hybrid model for JFM of 1998 can be considered to be impressive, however.

Judging solely on the JFM, 1998, forecast validation, the dynamical model can be considered to be the poorest performer of the three. The total precipitation forecast (Fig. 4c) misses the observations as severely as does the statistical model, but misses are generally in the opposite sense: most of California is overestimated. Overestimation is especially severe in the Central Valley 
and southeastern California. Small areas of underestimation of total precipitation are also evident on the eastern slope of the Sierra Nevada and California's southernmost tip. This large error spread suggests that statistically correcting RSM-produced forecast bias may be a complicated undertaking. In the full-dynamical approach, the forecasts of total precipitation, frequency, and daily intensity are all intimately related through model dynamics. Figures $4 \mathrm{f}$ and $4 \mathrm{i}$ show that the underestimation of total rainfall is due to underestimation of rainfall intensity, while much of the overestimation of total rainfall is due to overestimation of rainfall frequency. Only in limited areas of northern and coastal central California, where both frequency and intensity RSM forecasts validated well for JFM of 1998, could total precipitation have been forecast reasonably well for the right reasons.

\section{Summary and conclusions}

The following general points can be made to summarize the above results.

- The statistical model is a reasonable performer, robust to the sign of tropical forcing. Statistical models always will underestimate extremes. This bias may be amenable to statistical correction on a case-by-case basis.

- The hybrid model emerges as the best performer of the three, at least for El Niño winters. Performance improvement over the statistical approach may be sufficient to justify taking the extra step in complexity by employing the AGCM.

- The full-dynamical method does not appear to be operationally viable in the presence of much simpler, cheaper, and better-performing forecasting schemes. It must be stressed that this conclusion is based on a simple validation for only one forecasting event in California. Full-dynamical methods hold a promising potential that will be developed more fully through ongoing comparisons with simpler schemes. In the near future, development of an adequate RSM climatology will make it possible to assess model performance rigorously.

The following specific considerations and recommendations can be made in the name of long-range forecast improvement in the short term. The statistical scheme, which is limited by the length of available observations but not by the length of available model runs, would benefit from the inclusion of the interdecadal modulation of ENSO teleconnections to the southwestern United States by the North Pacific oscillation (Gershunov and Barnett 1998b; Gershunov et al. 1999). It is not currently clear whether the hybrid and full-dynamical approaches benefit from the explicit accounting for of midlatitude SST anomalies. AGCMs have not yet been tested rigorously for their ability to reproduce the observed NPO modulation of ENSO teleconnections. It is possible, however, that the El Niño skill improvement found in the hybrid model over its purely statistical counterpart is due partially to the inclusion of midlatitude SST anomalies into the forecasting scheme. In the case of the purely statistical model, the expected increase in skill due to the inclusion of NPO's effect upon ENSO teleconnections would be associated with a decrease in the spatial resolution of the precipitation forecast: adequately long precipitation records are available at fewer stations.

Hybrid-model skill deteriorates during La Niña winters. This results from the particular AGCM's bias in modeling the La Niña signal in midlatitude circulation, confounded by the linearity of the CCA downscaling procedure. A different AGCM, which better captures the La Niña signal, can be used in the second tier. A different set of canonical correlation variables can also be chosen for La Niña forecasting. In general, hybrid model predictability can be enhanced by selectively choosing an optimal set of canonical variates to represent variability of a specific variable at a specific location for a specific forcing (e.g., El Niño or La Niña). Of course, this approach significantly complicates the forecasting scheme, including skill estimation. The hybrid model, however, is the best performer for El Niño winters, including the winter of 1998, and hybrid-model optimization will be considered in a future paper.

The statistical and hybrid forecasting techniques can be applied easily to forecast any climate variable that can be derived from the available records. Variables such as frequencies of extreme precipitation and streamflow, and heating and cooling degree days are all amenable to operational long-range forecasting.

Acknowledgments. Thanks are due to Mary Tyree for running the AGCM and to Liqiang Sun for performing the RSM integrations. Conversations with Shyh Chen and John Roads provided intellectual stimulation. We are grateful to an anonymous reviewer for constructive criticism of the original manuscript. Funding for this project was provided by NOAA's Office of Global Programs through the Experimental Climate Prediction Center and California Applications Program and by NASA Grant NAG5-8292.

\section{REFERENCES}

Anderson, B., J. Roads, S. Chen, and H. Juang, 2000: Regional modeling of the low-level monsoon winds over the Gulf of California and southwest United States: Simulation and validation. J. Geophys. Res., in press.

Barnett, T. P., and R. Preisendorfer, 1987: Origins and levels of monthly and seasonal forecast skill for United States surface air temperatures determined by canonical correlation analysis. Mon. Wea. Rev., 115, 1825-1850.

_- and Coauthors, 1994: Forecasting global ENSO-related climate anomalies. Tellus, 46A, 381-397.

Bengtsson, L., U. Schlese, E. Roeckner, M. Latif, T. P. Barnett, and N. Graham, 1993: A two-tiered approach to long range climate forecasting. Science, 261, 1026-1029. 
Cayan, D. R., K. Redmond, and L. Riddle, 1999: ENSO and hydrologic extremes in the western United States. J. Climate, 12, 2881-2893.

Chen, S.-C., J. O. Roads, H.-M. H. Juang, and M. Kanamitsu, 1999: Global to regional simulations of California wintertime precipitation. J. Geophys. Res., 104, 31 517-31 532.

Efron, B., 1982: The Jackknife, the Bootstrap, and other Resampling Plans. Society for Industrial and Applied Mathematics, $92 \mathrm{pp}$.

Gershunov, A., 1998: ENSO influence on intraseasonal extreme rainfall and temperature frequencies in the contiguous United States: Implications for long-range predictability. J. Climate, 11, 31923203.

— extreme rainfall and temperature frequencies in the contiguous United States: Observations and model results. J. Climate, 11, $1575-1586$

_ , and — 1998b: Interdecadal modulation of ENSO teleconnections. Bull. Amer. Meteor. Soc., 79, 2715-2725.

$\longrightarrow,-$, and D. Cayan, 1999: North Pacific interdecadal oscillation seen as factor in ENSO-related North American climate anomalies. Eos, Trans. Amer. Geophys. Union, 80, 25-30.

Graham, N. E., and T. P. Barnett, 1995: ENSO and ENSO-related predictability. Part II: Northern Hemisphere 700-mb height predictions based on a hybrid coupled ENSO model. J. Climate, 8, 544-549.

Hoerling, M. P., A. Kumar, and M. Zhong, 1997: El Niño, La Niña, and the nonlinearity of their teleconnections. J. Climate, 10, 1769-1786.

Hong, S.-Y., and A. Leetmaa, 1999: An evaluation of the NCEP RSM for regional climate modeling. J. Climate, 12, 592-609.

Juang, H.-M. H., and M. Kanamitsu, 1994: The NMC nested regional spectral model. Mon. Wea. Rev., 122, 3-26.

- S.-Y. Hong, and M. Kanamitsu, 1997: The NCEP regional spectral model: An update. Bull. Amer. Meteor. Soc., 78, 21252143.

Mo, K., M. Kanamitsu, J. Wang, and A. Leetmaa, 2000: Ensemble regional climate prediction for the 1997/98 winter. Bull. Amer. Meteor. Soc., in press. 